Article

\title{
Building a Model for Financial Management of Digital Technologies in the Areas of Combinatorial Effects
}

\author{
Andrey A. Zaytsev ${ }^{1, *(D)}$, Roman S. Blizkyi ${ }^{2}$, Irina I. Rakhmeeva ${ }^{3}$ and Nikolay D. Dmitriev ${ }^{1}$ (D) \\ 1 Higher School of Engineering and Economics, Peter the Great Saint-Petersburg Polytechnic University, \\ Politekhnicheskaya Ulitsa, 29, 195251 St. Petersburg, Russia; dmitriev_nd@spbstu.ru \\ 2 Departments of Accounting Audit and Taxation, State University of Management, Ryazanskiy Prospekt, 99, \\ 109542 Moscow, Russia; blizkeyRS@gmail.com \\ 3 Departments of Regional Municipal Economy and Management, Ural State University of Economics, \\ Ulitsa 8 Marta, 62/45, 620144 Yekaterinburg, Russia; rahmeeva_ii@usue.ru \\ * Correspondence: zajtsev.aa@spbstu.ru or andrey_z7@mail.ru; Tel.: +7-911-248-59-67
}

Citation: Zaytsev, Andrey A.,

Roman S. Blizkyi, Irina I. Rakhmeeva, and Nikolay D. Dmitriev. 2021 Building a Model for Financial Management of Digital Technologies in the Areas of Combinatorial Effects. Economies 9: 52. https://doi.org/ 10.3390/economies 9020052

Academic Editor: Ralf Fendel

Received: 17 February 2021

Accepted: 26 March 2021

Published: 7 April 2021

Publisher's Note: MDPI stays neutral with regard to jurisdictional claims in published maps and institutional affiliations.

Copyright: (c) 2021 by the authors. Licensee MDPI, Basel, Switzerland. This article is an open access article distributed under the terms and conditions of the Creative Commons Attribution (CC BY) license (https:// creativecommons.org/licenses/by/ $4.0 /)$

\begin{abstract}
The race of states for digital leadership faces the challenges of digital transformation foresight, providing combinatorial effects and acceleration of digitalization processes, contributing to a more efficient allocation of limited financial resources. This situation determines the relevance of the authors' study, which aims to develop an appropriate model for the allocation of funds for digital technologies. The methodology of the study is based on the concepts of technological modes and cyclical development of the economy. The paper presents the authors' definition of the concept "digital space," which is new to Russian scientific literature. The key research method is mathematical modeling. The scientific novelty of the paper is chronological architectonics of digital transformations, built by the authors, and the model of distribution of financing under the investment constraints due to the trust limit of the society institutions, the time of fluctuations of the system of technological adaptation, and the response of the institutional environment to the digital limits of the transformations. The practical significance of the proposed models is the identified tandem interconnected digital technologies of the areas of combinatorial effects that accelerate the dynamics of Industry 4.0, as well as the resulting tools for the effective management of digital technology financing. The obtained theoretical and empirical results are desirable for the heads of government agencies, foundations, corporations, and development agencies, as well as enterprises interested in accelerating digital transformation and increasing strategic competitiveness in the digital space.
\end{abstract}

Keywords: digital space; technological mode; digital transformation; trends; digital economy; financial management; modeling

JEL Classification: O 00; F 29; F 21; E 27

\section{Introduction}

Trends of digital transformations of national economies during the period of intensified sanctions, i.e., the critical spread of the COVID-2019 pandemic, the isolation of state structures, increased protectionism in the functioning of the national economy, the fluctuations of free trade, and the negative manifestation of dysfunctions of public institutions, lead to intensified rates of introducing digital transformations and new business models and technologies in all areas of the economy and life. Virtually all spheres of the economy and life undergo global changes that contribute to the formation of new production and new needs (Maresova et al. 2018; Ustinovich et al. 2020). Digital technologies are becoming the basis of the economy in the context of the fourth industrial revolution, the change of technological modes, the formation of a new type of society and noonomics. Harmonization of economic relations of a completely new level determines the necessity of transition to innovative technologies capable of optimizing production and socio-economic processes, 
as well as making significant structural shifts in the national economy (Bodrunov 2018; Zaytsev et al. 2020; Dmitriev et al. 2020b). Transformation of economic relations leads to the evolution of institutional environment and a growing public demand for forming a digital law (Rimmer 2017), regulation of social relations between counterparties (Chae and Goh 2020), consumer and seller (Okhrimenko et al. 2019; Irons and Lallie 2014), and employee and employer (Ziaei Nafchi and Mohelska 2018), creation of publicly accessible and transparent development rules in the digital space (Blizkyi 2015), and contribution to the transformation of the structure of rental income in the economy (Zaytsev 2020).

Thus, the digital economy and its regulation are becoming an agenda for developed countries, which are competing for economic leadership in the world based on digital technologies, the fifth and sixth technological modes. Undertaking measures to create digital competitiveness is becoming a prerequisite for the sustainable development of business and national economies of all countries actively involved in international relations (Laitsou et al. 2020). However, the digital race is constrained by limited financial and intellectual resources, the abilities of proper foresight of digital transformations and their externalities. The presence of imbalances and uneven development of intellectual capital does not ensure realization of the economic potential for many business entities, which poses serious barriers to the maintenance of sustainability and stability of the national economy (Dmitriev 2018; Rayevnyeva and Touzani 2021). All this determines the relevance of forming a scientific basis for the management of cash flows to develop digital technologies.

The emergence of combinatorial effects from the accelerated development of digital technologies was most clearly manifested in 2020 in connection with the global pandemic of COVID-19 (Hyland-Wood et al. 2021; Zimmerling and Chen 2021). Entirely new strategic and technological trends were formed, aimed at changing the fundamental provisions for humanity's future. The global business shift in the technological and digital landscape has promoted greater plasticity for dynamic forming and reforming the technological basis of digitalization processes. Combinatorial effects began to emerge as the digital impact intensified, primarily focused on the interests of people in the prevailing negative conditions. The business ecosystem began to adjust to circumstances and transform its technological space, creating opportunities to provide its services regardless of the location of consumers and partners. Influencing stakeholders in the pandemic conditions is now possible virtually regardless of their territorial location, i.e., there has been a significant acceleration in the use of remote channels of interaction. The digitalization of 2020 has touched virtually every industry and country, shaping an entirely new cybersecurity paradigm and focusing efforts on building digital business models that are location-independent. Maintaining organizational resilience and building a technology architecture facilitated rapid adaptation to overcome the potential challenges of our time. Such conditions have led to large-scale economic consequences, reinforcing the existing synergy of scientific and technological trends, complementing each other in the creation of a new digital world.

The primary contribution of the research is a comprehensive approach to forecasting the development of different directions of digital technology transformations. The authors put forward a new reinterpretation of technology as a process consisting of an innovation multiplier, a knowledge spillover, and diffusions of digital transformations that are inextricably linked to the accelerator of combinatorial effects of digital transformations. The conceptual view expands the horizon of knowledge in the understanding of the proposed scientific and methodological approaches to assessing the zones of innovation of the combinatorial effects of digital transformations, while highlighting the economic and mathematical model of the distribution of induced investments of the distribution of the volume of financing in the conditions of investment restrictions.

The aim of the study is to develop a model for the allocation of funds for digital technologies in the context of the outlined challenges and constraints to maximize the combinatorial effect and accelerate digital development.

The paper used general scientific and special methods, which allowed achieving the following key objectives: 
- Definition of the concept "digital space" as part of the formation of the combinatorial effect area of accelerated development of digital technologies;

- Construction of the architectonics of digital transformations in the time series by means of a graphical diagram, as well as the identification of tandem interconnected areas of combinatorial effects that accelerate the dynamics of the basic digital technologies of Industry 4.0;

- Development of a mathematical model for the distribution of funding under-investment constraints, mainly due to the limit of trust of society institutions, the time of fluctuations of the system of technological adaptation and the response of the institutional environment to the digital limits of transformation.

\section{Literature Review}

Digital technologies are increasingly transforming the world, changing human expectations and values, changing business priorities and development models, revolutionizing the industrial and socio-economic status of states, and, as a result, creating a combinatorial effect of accelerating change. Intellectual capital is a non-competitive benefit and has a diffuse distribution pattern (Kingiri and Fu 2020; Park and Koo 2020; Zhilenkova et al. 2019), which leads to the synergistic effect of economic development based on the technologies of Industry 4.0. Global digitalization leads to the reduction of the digital divide between different population groups and contributes to the creation of completely new interconnections between social and economic relations, based on the achievements of scientific and technological progress (Okhrimenko et al. 2019; Yakovlev et al. 2019).

In this study, the development of digital technologies is considered through the prism of the concepts of scientifically-discussed concepts and approaches of the digital economy. One of the central concepts is the "digital space." It is under the influence of digitalization formed by the high-performance infrastructure, within which the scientific and technical apparatus for the maintenance, use, and application of innovative processes leading to a qualitative technological breakthrough is developed (Babskova et al. 2019; Graham and Guy 2002; Schou and Hjelholt 2019). The authors interpret "digital space" as a system of intellectual resources, information, and data that ensures interaction with the material world through cyber-physical systems and with individuals through digital technologies. There are inequalities in the digital space in terms of access to the Internet and digital technologies, the level of knowledge and competencies for the successful application of digital technologies, which leads to increasing economic inequalities, increasing asymmetries of information and a shift of ruling elites toward technocrats.

In the context of this study, we analyzed the scientific concepts of the publications in the electronic scientific library (elibrary.ru). Figure 1 shows the evolution of the term "digital space" in Russian scientific literature and the growth of interest in this object of research (the number of publications that use this concept is shown by year).

Particular attention to the issues of the relationship between time and the dynamics of technology fluctuations to the dominant technological mode is paid in the fundamental scientific works by: Arrigi [1994] (Arrigi [1994] 2006), Schumpeter (1939), Kondratieff [1925] (Kondratieff [1925] 1984), Glazyev et al. (2018). The ideas in these works became the methodological basis of the authors' research.

Predicting the development of technologies, a new mode and economy becomes the focus of the global scientific community in the 21st century (the main global trends have been considered in a number of studies (Al Muhayfith and Shaiti 2020; Bataev 2018; Lynn et al. 2020)). The scientific paradigm is also being transformed by global digital pressure, which is responsible for its constant dynamics in the surrounding space (Bailey et al. 2020; Clegg 2011). Scientists cannot but notice the loss of balance in economic development, the turbulence of emerging trends, and the variability of basic conditions and preconditions. The authors relied on the basic concepts of mathematical modeling for the digital economy proposed in the works of contemporary economists (Galbraith and Hodgson 2018; De Gaetano 2018; Yakovlev et al. 2019). 


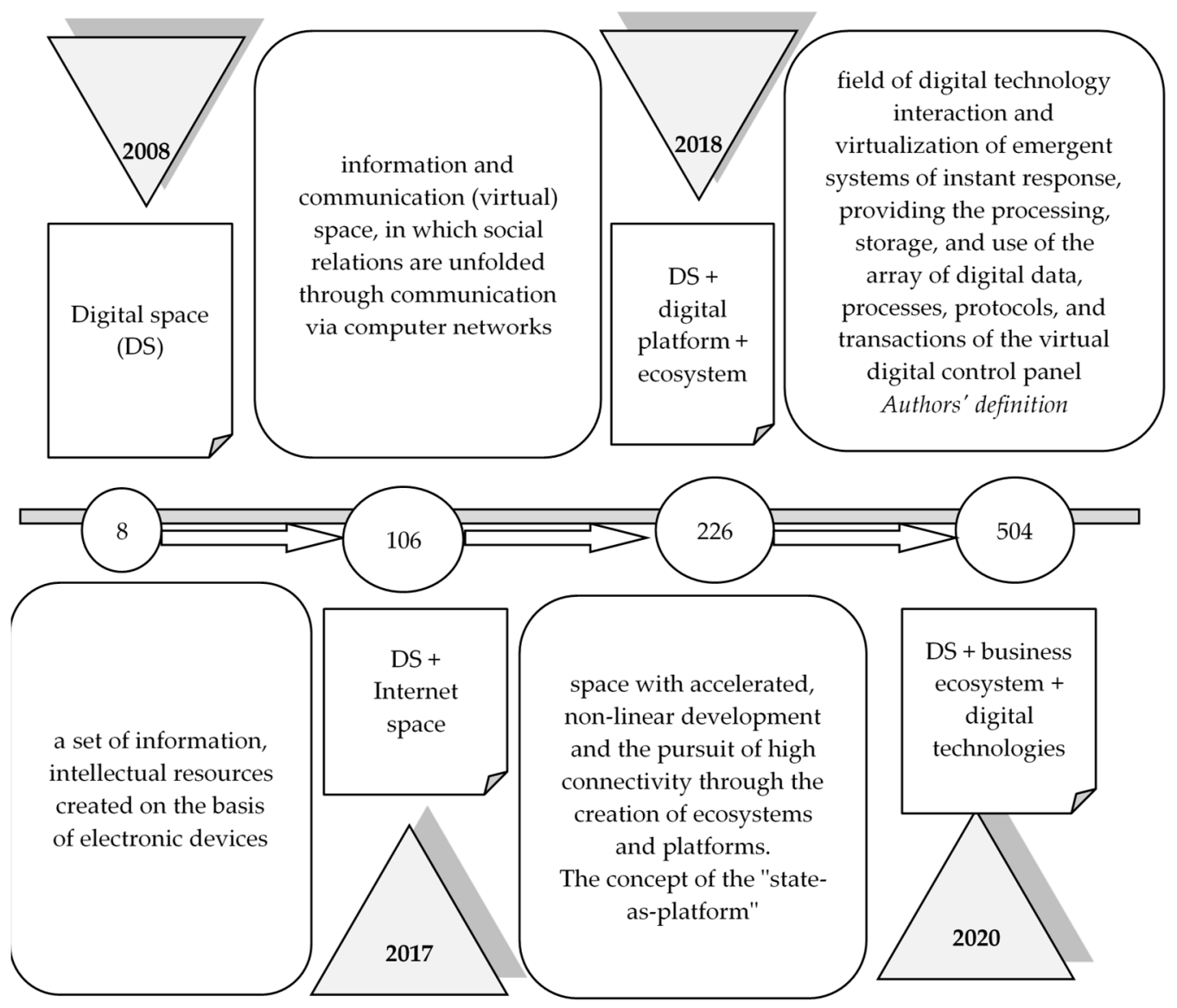

Figure 1. Evolution of the "digital space" concept in Russian scientific literature.

It is the use of the mathematical apparatus within the framework of evaluating the economic phenomena that contributes to the most effective analysis of their essential characteristics and provisions. Digital processes, as well as many other economic phenomena, such as investment analysis, problems of rationalization, and optimization of economic activity, can be subject to mathematical modeling, which provides an opportunity to determine the sustainability of economic system development from the position of technological restructuring. The methodological significance of the models built consists of predicting the parameters of sustainability and stability of digital functioning, depending on the state of financial flows. Additionally, mathematical modeling to determine the qualitative provisions of digital processes may not be limited to the classical tools of the economic and mathematical analysis, such as correlation and regression analysis, fuzzy logic, and real option, but also provides opportunities to form new ways to solve the problem (Kichigin et al. 2019; Rodionov et al. 2018).

In the scientific community, the issues of the formation of the digital space in the context of the global COVID-19 pandemic have become particularly acute. The current negative environment in the macroeconomic environment determines new trends in digital transformation, which was noted in previous articles (Hyland-Wood et al. 2021; Zimmerling and Chen 2021). In 2020, major transformations of national economies took place, determining the accelerated dynamics of the transition to digital technologies, which is a serious opportunity to obtain new combinatorial effects. In almost all countries, the spread of technology, primarily in the digital environment, determines the fluctuations in the scientific and technical sphere to the dominant technological order (Cavusgil 2021; Ghauri et al. 2021). Nevertheless, despite the development of problems, there are still gaps in scientific and practical approaches to the assessment of digital technologies in the areas of combinatorial effects, which does not allow us to form models for managing 
their financing. The mediating influence of digital innovation on the relationship between the efficiency of the economic system and digital orientation opens up a whole range of digital opportunities, which requires the search for a new conceptual framework (Khin and Ho 2020). It is worth noting that digital innovations in the context of a pandemic are becoming a real tool not only in the qualitative transformation of human life, but also open up opportunities for technological reorientation of economic activity.

First, digital growth is observed in the corporate sector, due to the spread of Industry 4.0 innovations, which include intelligent services, blockchain technology, and cybersecurity systems (Nurk 2021). For example, one article (Kotishwar 2020) examined the use of blockchain technology based on the statistical method of discriminant analysis and drew conclusions about the possibility of obtaining effects from digital sources by reducing transaction costs and comprehensively improving security. Another article (Spilnyk et al. 2020) analyzed the use of information systems and information technologies in the practice of accounting and financial reporting, which allows increasing economic efficiency and strengthen digital relationships. It can be concluded that the materials of scientific research allow us to consider the digital space as an element of creating value potential.

\section{Methodology}

\subsection{Obtaining and Collecting Data}

The paper uses general scientific methods and techniques that allowed us to solve problems, identify the processes and interaction of variables of the digital technology finance management model in the areas of combinatorial effects:

- $\quad$ Formal logic in the analysis, generalization and systematization of the material;

- Historical and retrospective analysis for the study of the formation and evolution of the concept of "digital space";

- A systematic approach and an institutional-evolutionary method for studying the development of digital transformations in the world;

- Analysis and synthesis to determine the features of tandem connections of zones of combinatorial effects and their specifics of accelerations in digital technologies of Industry 4.0;

- System and statistical analysis, as well as an economic and mathematical method for forming a model for the distribution of the amount of financing by induced investments in the conditions of restrictions in the relevant zones.

According to the results of the analysis of the key values created by digitalization in business and society, the experts of the Digital Transformation Initiative of the World Economic Forum (WEF 2018) made predictions on the acceleration of digital change. Thus, according to the forecast, more than 1 trillion devices will be connected to the Internet by 2030 , the rapid reduction in the cost of advanced digital technologies will lead to the formation of tandem interconnections of technologies significantly accelerating the rate of development of combinatorial effects of digital technology development (Table 1).

Technology in this case takes on a new reinterpretation as a process of innovation multiplier, knowledge spillover, and diffusions of digital transformations inseparable from the accelerator of combinatorial effects of digital transformations. Innovative activities require significant financial resources with simultaneously high investment risk. While the issues of R\&D investment at the level of an individual enterprise (Ko et al. 2018; Maydanova and Ilin 2019) or state (Agumbayeva et al. 2019; Vukovic et al. 2017) are now sufficiently studied, at the macro level, taking into consideration synergetic, combinatorial effects of different innovations, the methodology is poorly developed (Bataev 2018; De Gaetano 2018). 
Table 1. Forecast of the digital transformation index in the world, $\%$ *

\begin{tabular}{|c|c|c|c|c|c|c|c|c|c|c|}
\hline \multirow{2}{*}{ Basic Directions } & \multirow{2}{*}{ Unit of Measure } & \multicolumn{9}{|c|}{ Period } \\
\hline & & 1950 & 1960 & 1970 & 1980 & 1990 & 2000 & 2010 & 2020 & 2030 \\
\hline \multirow{2}{*}{ Mainframe } & $\%$ & 0 & 4 & 18 & 30 & 35 & 37 & 36 & 32 & 28 \\
\hline & unit weight & & 1.00 & 0.78 & 0.45 & 0.28 & 0.21 & 0.13 & 0.08 & 0.06 \\
\hline \multirow{2}{*}{ Client-server and PCs } & $\%$ & & 0 & 5 & 28 & 47 & 58 & 60 & $58^{\mathrm{A}}$ & $55^{\mathrm{C}}$ \\
\hline & unit weight & & 0.00 & 0.22 & 0.42 & 0.38 & 0.34 & 0.22 & 0.14 & 0.12 \\
\hline \multirow{2}{*}{ Web 1.0 e-Commerce } & $\%$ & & & 0 & 8 & 40 & 60 & 66 & $65^{\mathrm{A}}$ & $63^{C}$ \\
\hline & unit weight & & & 0.00 & 0.12 & 0.32 & 0.35 & 0.25 & 0.16 & 0.13 \\
\hline \multirow{2}{*}{$\begin{array}{l}\text { Web } 2.0 \text { cloud, mobile, } \\
\text { ERP/BPM/CRM/systems }\end{array}$} & $\%$ & & & & 0 & 3 & 12 & 58 & $82^{\mathrm{A}}$ & $89^{\mathrm{B}}$ \\
\hline & unit weight & & & & 0.00 & 0.02 & 0.07 & 0.22 & 0.20 & 0.19 \\
\hline \multirow{2}{*}{ Big Data, Blockchain } & $\%$ & & & & & 0 & 6 & 40 & $77^{\mathrm{A}}$ & $94^{\mathrm{B}}$ \\
\hline & unit weight & & & & & 0.00 & 0.03 & 0.15 & 0.19 & 0.20 \\
\hline \multirow[t]{2}{*}{$\begin{array}{l}\text { IoT, Smart Machine, Machine } \\
\text { Learning, Digital Shadows }\end{array}$} & $\%$ & & & & & & 0 & 9 & $77^{\mathrm{A}}$ & $98^{\mathrm{B}}$ \\
\hline & unit weight & & & & & & 0.00 & 0.03 & 0.19 & 0.21 \\
\hline \multirow[t]{2}{*}{ Artificial intellect, Robotization } & $\%$ & & & & & & & 0 & 15 & $50^{C}$ \\
\hline & unit weight & & & & & & & 0.00 & 0.04 & 0.10 \\
\hline \multirow{2}{*}{ Total: } & $\%$ & 0 & 4 & 23 & 66 & 125 & 173 & 269 & 406 & 477 \\
\hline & unit weight & 1 & 1 & 1 & 1 & 1 & 1 & 1 & 1 & 1 \\
\hline
\end{tabular}

* indexes A, B, and C show that the direction belongs to the Area of combinatorial effects (Figure 2). Note: according to the data of DTI (WEF 2018).

\subsection{Sample and Its Context}

Data analysis of the level of development of basic digital technologies focuses on the response of the two variables of time $(t)$ and the digital transformation index (DTI) in the world, expressed by a stable perception of the cyclical development of the technological mode in the changes of digital solutions implemented in the business processes of economic entities.

We also note that interpreting the data in Table 1 in a graphical format, synchronizing them with scientific discoveries of the cycles of economic conjuncture by N. Kondratieff (Kondratieff [1925] 1984), as well as the basic directions of technological transformation of the European concept of Industry 4.0 (Deloitte Insights 2019), formed a dot diagram of tandem interconnections of the areas of combinatorial effects of acceleration (Figure 2).

Interpretation of the results from the diagram in Figure 2 allowed us to assume the most important areas of combinatorial effects of acceleration of basic digital technologies and assess the possible consequences of their changes. The research processes indicate the formation of tandem interconnections between the development of basic digital technologies and alternatives of the set of Pareto optimal solutions. The authors identified three special key areas A, B, and C, accelerating development and entailing new transformations in the digital economy. A model of allocation of financial resources in conditions of financial constraints and investment deficit, caused primarily by barriers and limits to adaptation of digital transformations by the environment, was presented. An example of confirmation of these hypotheses in the study were the assumptions and suppositions of a probabilistic model of redistribution of resources of one of the selected areas of acceleration of basic digital technologies. 


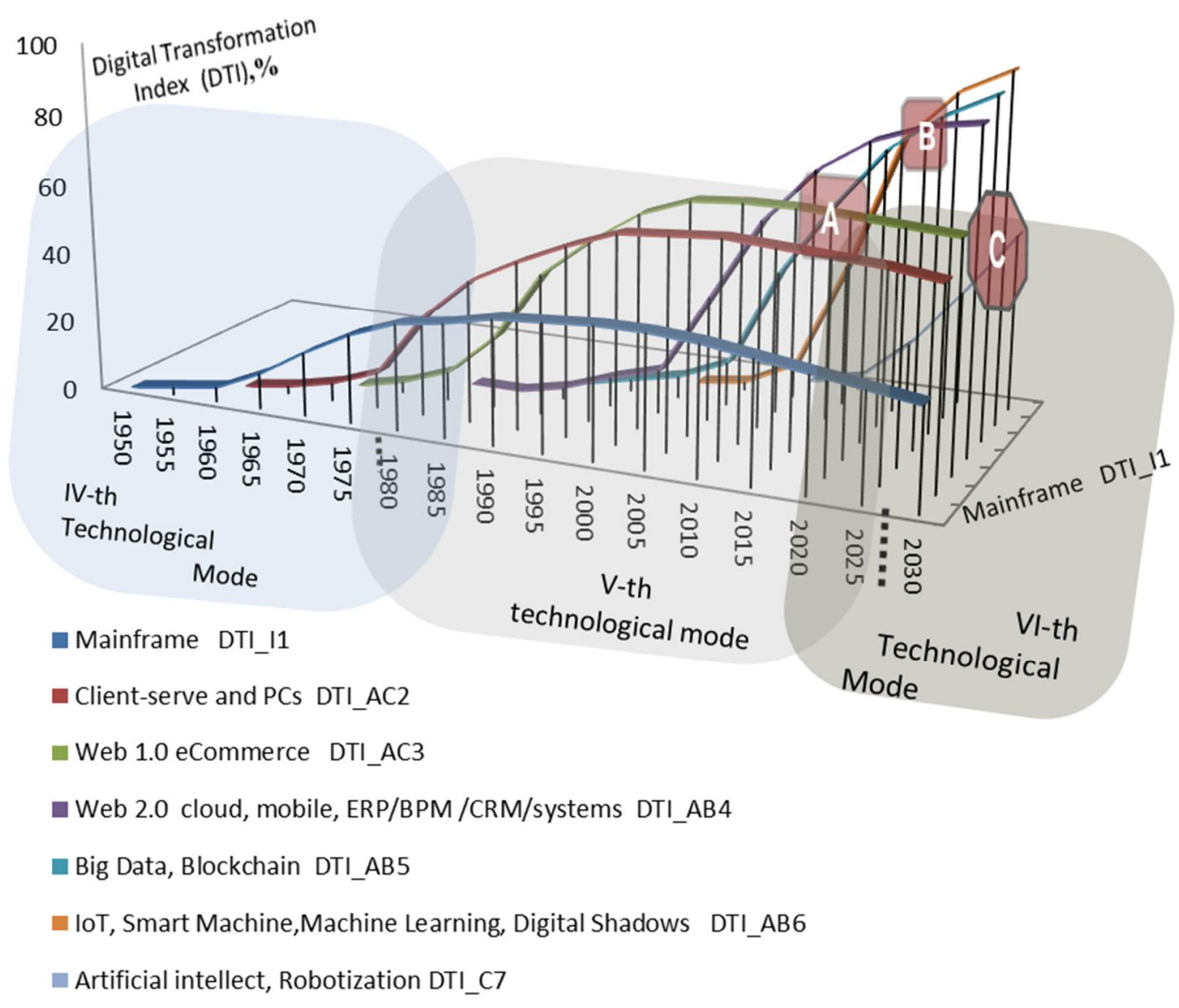

Figure 2. Tandem interconnections of the areas of combinatorial effects of acceleration of the basic digital technologies of Industry 4.0 .

For a long time in the scientific community, it was believed that the duration of the cycle of the economic conjuncture depended mainly on the acceleration of scientific and technological progress. Thus, in the works of the French economist on the duration of cycles C. Juglar, this fact was proven (Juglar 1862). However, in the scientific works of Professors A.A. Akaev and V.A. Sadovnichii (Akaev and Sadovnichii 2018), it was suggested that changes in the economic conjuncture can be approximated by a sinusoidal curve, and the role of the basis of transformation plays the power of the accelerator, i.e., entrepreneurial activity. G.A. Adamova (Adamova 2019) noted indirect signs of accelerator power development in major companies through management flexibility and specificity of their structures.

In a linear form, the accelerator is expressed as follows (Allen 1963) (Formula (1)):

$$
I(t)=v \frac{d}{d t} Y(t)
$$

where $Y(t)$ is the output (income); $I(t)$ is the amount of the induced capital investment; and $v$ is the investment coefficient.

In this case, under the induced investment (hereinafter II) we will understand the investment of financial resources (investments) in the products (results) of digital transformations, caused by the restructuring and development of the needs of a new type of society and noonomics.

Let us define a model for the distribution of the II funding under the constraints of the corresponding areas (Figure 2) of the acceleration of economies. Let us make several assumptions for digital transformation: 
(a) The volume of II is limited in its size and this is mainly due to the limit of trust of public institutions, the time of fluctuations in the system of technological adaptation, and the response of the institutional environment to the digital limits of transformation;

(b) For each individual state under the conditions of different thresholds of "entry" into the digital transformation of economies, there will be different priorities of development areas for basic digital technologies, so the concept of globalization requires a set of uniform rules in coordination with a central, coordinating institution of transformation;

(c) Under the conditions of uncertainty, it is required to build a matrix for determining alternative solutions, in which certain parameters will correspond to the indicators of the state of II at the digital transformation index (DTI) of different areas of combinatorial effects in the time interval $\left(T_{0} \leq t<T_{1}\right)$.

Let us denote $I(t)_{D T I(i, j)}$ as the volume of required (recommended) II, corresponding to the $i$-th direction of the $j$-th area, then the total volume: $I(t)=\sum_{0<i<m} 0<j<n ~ I(t)_{D T I_{(i, j)}}$ is the total volume of required II ( $m$ is the number of priority directions, $n$ is the number of areas of combinatorial effects), and I(s) is the formed volume of II. Additionally, a situation is possible in which the inequality can take the position of $I(t)>I(s)$, i.e., there are not enough of attracted II to cover the demand for them. Here, it is necessary to correlate the decisions made on the basis of assumption $b$. Let us denote the expert ratings of the degree of priority to the $i$-th direction of the $j$-th area $\mu_{(i, j)}$ determined from Table 1 of the forecast of digital transformations with a scale of importance scores from 1 to 10 , where 1 is a low priority, and 10 is the most significant priority. Moreover, taking into consideration the fact of Pareto optimality (the first and second welfare theorems), let us introduce the deflator of utility distribution to the $i$-th direction of the $j$-th area. In this case, all the required directions of II $I(t) D T I_{i, j}$ resources in the time interval $\left(T_{0} \leq t<T_{1}\right)$ will tend to choose the optimal distribution $I(s)$ with allowance for expert estimates and the state of the deflator of utility distribution (Formula (2)):

$$
I(s)=\sum_{0<i<m 0<j<n} \min \left(I(t)_{D T I i, j} ; \alpha \mu_{(i, j)}\right) \text { with } \mathrm{T}_{0} \leq \mathrm{t}<\mathrm{T}_{1},
$$

where $\alpha_{(i, j)}$ the deflator of utility distribution is determined as (Formula (3)):

$$
\alpha_{(i, j)}=\frac{I(t)_{D T I i, j}}{\mu_{(i, j)}},
$$

It is necessary to determine the position at which the formed volume of investments $I(s)$ in certain intervals, grouped in ascending order $I(t) D T I_{i, j}$, will create events $\tau$, at which the following inequalities will be observed (Formulas (4) and (5)):

$$
\begin{gathered}
\sum_{i=1}^{\tau} I(t)_{D T I_{(i, j)}}+\alpha_{\tau} \sum_{i=\tau+1}^{n} \mu_{(i, j)} \leq I(s), \\
\sum_{i=1}^{\tau+1} I(t)_{D T I_{(i, j)}}+\alpha_{\tau+1} \sum_{i=\tau+2}^{n} \mu_{(i, j)}>I(s),
\end{gathered}
$$

Thus, let us transform formalization 4 from the first inequality, taking into consideration the volume of formed $I(s)$. The value of the deflator of the investment utility distribution (Formula (6)):

$$
\bar{\alpha}=\frac{I(s)-\sum_{i=1}^{\tau} I(t)_{D T I_{(i, j)}}}{\sum_{i=\tau+1}^{n} \mu_{(i, j)}}
$$

\section{Results}

Let us conduct an experiment using our proposed formatted hypothesis on the approach of the global distribution of II volume corresponding to different areas of combinatorial effects of accelerating digital transformations of economies. 
Let us form a table of data on the required investment of financial resources in the directions of digital transformation, as defined by the research of the DTI experts (WEF 2018) in Table 2.

Table 2. Data on required investments in the directions of digital transformation for 2020, bln. dollars*.

\begin{tabular}{|c|c|c|c|c|c|c|}
\hline Basic Directions & DTI_AC2 & DTI_AC3 & DTI_AB4 & DTI_AB5 & DTI_AB6 & DTI_C7 \\
\hline \multirow{3}{*}{$\begin{array}{c}\text { Area of combinatorial } \\
\text { effects }\end{array}$} & & & $\mathrm{A}$ & & & \\
\hline & & B & & & & \\
\hline & C & C & & & & C \\
\hline Period & - & 242.6 & 252.34 & 378.46 & 1019 & 533.7 \\
\hline
\end{tabular}

Let us fill Table 3 with the initial data and calculate and model the parameters for 2020 in the investment allocation matrix under the condition of limited financial investments of 1000 billion dollars.

Table 3. Investment allocation matrix for 2020 under the condition of limited investments (by the example of area B).

\begin{tabular}{|c|c|c|c|c|c|}
\hline & \multicolumn{5}{|c|}{ Area $B_{(1)}$} \\
\hline & $I(t)_{D T I_{i, j}}$ & $\mu_{(i, j)}$ & $\alpha_{i, j}$ & $\bar{\alpha}$ & $\mathrm{I}(\mathrm{S})$ \\
\hline DTI_AB4 & 252.34 & 8.9 & 28.35280899 & & \\
\hline DTI_AB5 & 378.46 & 9.4 & 40.26170213 & & \\
\hline DTI_AB6 & 1019 & 9.8 & 103.9795918 & & \\
\hline Total: & 1649.8 & - & & & 1000 \\
\hline
\end{tabular}

Let us assume that $\bar{\alpha}=\mathrm{a}_{1}=28,4(\tau=1)$ :

$$
\begin{gathered}
\sum_{i=1}^{\tau} I(t)_{D T I_{(A B 4, B)}}=I(t)_{D T I_{A B 4, B}}+\alpha_{D T I_{A B 4, B}} \times\left(\mu_{(A B 5, B)}+\mu_{(A B 6, B)}\right)=252.34+28.35280899 \times 19.2=796.7139326<1000 \\
\sum_{i=1}^{\tau} I(t)_{D T I_{(A B 5, B)}}=I(t)_{D T I_{A B 4, B}}+I(t)_{D T I_{A B 5, B}}+\alpha_{D T I_{A B 5, B}} \times\left(\mu_{(A B 6, B)}\right)=252.34+378.46+40.26170213 \times 9.8=1025.364681>1000 \\
\sum_{i=1}^{\tau} I(t)_{D T I_{(A B G, B)}}=I(t)_{D T I_{A B 4, B}}+I(t)_{D T I_{A B 5, B}}+I(t)_{D T I_{A B G, B}}=252.34+378.46+1019=1649.8>1000
\end{gathered}
$$

The last two expressions do not meet the desired condition of Formula (2) at 1000, so the calculation for the value of the deflator of investment utility distribution will look as follows:

$$
\bar{\alpha}=(1000-252.34) / 19.2=38.940625
$$

Thus, the approach of reallocation under the constraints of funding for area B will give the following parameters of reallocation of resources:

$I(s)_{D T I_{(A B 4, B)}}=252.34$ bln. dollars;
$I(t)_{D T I_{(A B 5, B)}}=366.04$ bln. dollars;
$I(t)_{D T I_{(A B 6, B)}}=381.62$ bln. dollars.

\section{Discussion}

It is impossible to imagine the modern innovation sector without the use of digitalization elements, which are becoming the key driver of sustainable development in the high-tech sector. This practice has already become a global trend and demonstrates strategic competitiveness of national economies that cannot succeed in the global economic arena without the fundamental development of scientific and technological progress (Bodrunov 2018; Kolyasnikov and Kelchevskaya 2020). Conceptual views on the issues of building a digital economy in a dynamic socio-cultural and consumer-oriented space 
are stipulated by the need to implement complex programs and projects highlighting the maximum number of individual aspects and directions of digitalization, as well as its final results for the socio-economic development of the country and society. The strategy of information society development is applied in many states and becomes an important structural element in the sustainable development of the nation (Degtereva et al. 2019; Schou and Hjelholt 2019; Vasetskaya and Gaevskaia 2019).

The digital age dictates new rules for all players, and to achieve global leadership, it is necessary to ensure the search for combinatorial effects, the financing of which should become the target of state policy in the field of digitalization. However, if we consider the Russian practice, the country's technological development, despite its significant progress, is not at a sufficiently high level. Intensification of innovation processes is stalled due to weak development of digital institutions that hinder attraction of financial flows into technological segments of the economy (Bataev et al. 2018; Rayevnyeva and Touzani 2021). A colossal role in the intensification of intellectual processes is played by the legal framework, which should timely respond to new technological developments, which in the digital age can include big data, cloud computing, search engines, and social networks (Rimmer 2017). In many countries, including Russia, there are serious difficulties in regulating the relationship between individual items of intellectual property that contribute to the incoming digital development of the national economy. These disputes cause imperfect institutional environment and pose serious barriers to the formation of the country's digital potential (Ergunova et al. 2019; Ovchinnikov et al. 2020; Rakhmeeva 2019).

The achievements of Industry 4.0 have the greatest significance in highly developed countries, because their financing is most beneficial due to the presence of a favorable institutional environment and opportunities to benefit from competitive advantages. In general, the technological advancement seriously transforms the existing system of the economy and leads to the need to use the most promising technologies in production relations. For example, automation and lean production have long been significant elements in achieving strategic success, while at the same time, the dynamics of the digital space makes it possible to optimize economic processes more effectively and using more available tools of influence (Clegg 2011; Dmitriev et al. 2020a; Ziaei Nafchi and Mohelska 2018). The search for combinatorial effects of digital technologies in the production sphere is the most relevant today from the position of the possibility of obtaining global benefits not only from intensive ways to increase productivity, but also the ability to realize the competitive potential of economic actors.

The trends of the new industrial revolution determine strengthening of the relationship between economic growth and innovation, the substantive components of which ensure the search for combinatorial effects from development of the key areas of Industry 4.0. Maximizing the benefits of financing such areas is only one of the numerous effects required to increase competitiveness and gain market power in a particular segment. Digitalization as one of the basic directions of the information society in the 21st century provides an opportunity to create new ideas and realize goals that were previously considered unattainable, which together provides the nation with an opportunity to improve its technological potential through creative destruction. The desire to obtain combinatorial effects from dynamically developing structural-logical processes in economic systems allows us to revise certain parameters of the neoclassical paradigm and to determine the future of digital technologies in the national economic system (Bailey et al. 2020; Blizkyi 2015; Zaytsev et al. 2020).

The results of the study are particularly relevant in the current conditions of macroeconomic instability, when the existing financial distribution systems are negatively affected due to the global COVID-19 pandemic. The optimal allocation of available financial resources among priority digital projects will contribute to a comprehensive increase in economic efficiency (Hyland-Wood et al. 2021; Zimmerling and Chen 2021). Using the possibilities of building new approaches based on the developed tools will allow to rationalize the systematic use of digital innovations both in existing economic systems, and 
will provide the potential for creating completely new conceptual opportunities for newly created system entities (Khin and Ho 2020). Accelerating technological progress requires constant updating of forecasts and operational management of the regulatory environment and financial flows. The scientific community faces the important task of providing key management decision-makers with a theoretical and methodological basis in the face of growing uncertainty and cardinal digital and institutional transformations. Acceleration of technological progress requires constant actualization of forecasts and operational management of the regulatory environment and financial flows. The scientific community faces the crucial task of providing those who make key managerial decisions with a theoretical and methodological basis under conditions of growing uncertainty and cardinal digital and institutional transformations.

\section{Conclusions}

The results of the study can be used by managers of funds, corporations and development agencies, as well as individual enterprises to determine the key areas of investment. The mathematical model of the distribution of the volume of financing in the conditions of investment restrictions can be used as a tool for effective management of the financing of digital technologies by the authorities of various levels.

Accelerating technological progress requires constant updating of forecasts and operational management of the regulatory environment and financial flows. The scientific community faces an important task of providing key management decision-makers with a theoretical and methodological basis in the face of growing uncertainty and cardinal digital and institutional transformations.

Based on the results obtained, the correlation and regression analysis methodology, the Robert Solow model, and the "expert panels" method, a new scientific hypothesis will be put forward in subsequent studies regarding the development of compensatory mechanisms for decision support and prioritization.

\subsection{The Main Contributions}

The chronological architectonics of digital transformations built in the paper (Figure 2) allows identifying tandem interconnected digital technologies of combinatorial effect areas that accelerate the dynamics of Industry 4.0. In particular, the authors highlight the promising combinatorics of cloud technologies, big data, and the Internet of Things (area B). Their tandem use is already observed in many industries and countries today, especially where there is a positive practice of spreading digital financial innovation (Degtereva et al. 2019; Kingiri and Fu 2020). Such use is observed both in everyday activities in the interaction between households and the business sector (Al Muhayfith and Shaiti 2020; Lynn et al. 2020), and in government regulation (e.g., the planned transition to digital control and supervision and governance based on big data (Ergunova et al. 2019; Ovchinnikov et al. 2020; Rakhmeeva 2019)).

The study of development of digital technologies is considered through the prism of the concepts of scientifically debated concepts and mathematical interpolations of data in the conditions of the digital economy development. The interpretation of formalizing the proposed model of financial management of the combinatorial effect areas determines the scientific challenge and the need to actualize the processes of assessing the proportionality of the financial resource investments and qualitative parameters of development for its elements in the digital space. The authors, substantiating the approaches to the selection of model elements, relied on the principle of zonal integration of effects, proceeding, among other things, from monitoring of statistical and scientific observations and trends of development of digital technologies.

\subsection{The Implications of This Study for Practice and Theory}

Digital environment of the information society is formed at a high level of innovation, achieving what is impossible without attracting significant financial resources. The priorities 
of the national economic development on the basis of innovative elements lead to development of digital competencies in the human capital and to formation of digital entrepreneurship, the functioning of which is based on the use of digital technologies (Babskova et al. 2019; Chae and Goh 2020). In this regard, the results of this study may find practical application in the implementation of management measures by the heads of foundations, corporations, and development agencies (Maydanova and Ilin 2019; Rodionov et al. 2018), as well as individual business structures (Kolyasnikov and Kelchevskaya 2020; Maskuriy et al. 2019) to identify key areas of investment. The mathematical model of funding allocation under investment constraints can be used as a tool for effective financial management of digital technologies by different levels of authorities (Barzotto et al. 2020; Grodach and Gibson 2019; Lapidus et al. 2019; Nikitina and Ruchkin 2019).

\subsection{Study Limitations}

A number of significant assumptions can be distinguished on the basis of discussions of validity of the proposed model and, as a result, an assessment of the achieved forecast states of the parameters of reallocation of limited financial resources. Studies based on international research data of experts of Digital Transformation Initiative lead to the interpolation of the data of the three areas affecting the acceleration of digital change.

\subsection{The Future Research Agenda}

Depending on the criteria of the priority of economies, research needs to establish how to allocate different parameters of priorities with their interpolation of data into different mechanisms of financing to further develop digital technologies. To expand the boundaries of scientific hypotheses, we will need to allocate mechanisms for absolute, direct, and inverse priorities of financing digital technologies.

Author Contributions: Conceptualization, R.S.B. and I.I.R.; methodology, R.S.B. and I.I.R.; validation, N.D.D., R.S.B. and I.I.R.; formal analysis, N.D.D.; investigation, N.D.D. and I.I.R.; resources, R.S.B.; data curation, A.A.Z. and N.D.D.; writing-original draft preparation, R.S.B. and I.I.R.; writingreview and editing, A.A.Z. and N.D.D.; visualization, I.I.R.; project administration, A.A.Z. All authors have read and agreed to the published version of the manuscript.

Funding: Not applicable.

Institutional Review Board Statement: Not applicable.

Informed Consent Statement: Not applicable.

Data Availability Statement: Data available in a publicly accessible repository.

Conflicts of Interest: The authors declare no conflict of interest.

\section{References}

Adamova, Gulnara A. 2019. Actual problems of accounting organization on the financial responsibility centers. Vestnik Universiteta 5: 116-20. [CrossRef]

Agumbayeva, Assia, Elena Chmyshenko, Nikolai Pulyaev, Dmitryi Bunkovsky, Kiril Kolesov, and Elmira Amirova. 2019. Industrial transformation of Kazakhstan in digitalizations era. Journal of Advanced Research in Law and Economics 10: 1861-67.

Akaev, Askar A., and Victor A. Sadovnichii. 2018. Mathematical models for calculating the development dynamics in the era of digital economy. Doklady Mathematics 98: 526-31. [CrossRef]

Al Muhayfith, Sara, and Hani Shaiti. 2020. The Impact of Enterprise Resource Planning on Business Performance: With the Discussion on Its Relationship with Open Innovation. Journal of Open Innovation: Technology, Market, and Complexity 6: 87. [CrossRef]

Allen, Roy D. 1963. Mathematical Economics. Moscow: Publishing House of Foreign Literature.

Arrigi, Giovanni. 2006. The Long Twentieth Century: Money, Power and the Origins of Our Time. Moscow: Territory of the Future, p. 472. First published 1994.

Babskova, Olga, Olga Nadezhina, and Olga Zaborovskaya. 2019. Innovative activities in a region in the conditions of the development of the digital environment. International Journal of Innovative Technology and Exploring Engineering 8: 4361-65. [CrossRef] 
Bailey, David, Jennifer Clark, Alessandra Colombelli, Carlo Corradini, Lisa De Propris, Ben Derudder, Ugo Fratesi, Michael Fritsch, John Harrison, Madeleine Hatfield, and et al. 2020. Rethinking regions in turbulent times. Regional Studies 54: 1-4. [CrossRef]

Barzotto, Mariachiara, Carlo Corradini, Felicia Fai, Sandrine Labory, and Philip R. Tomlinson. 2020. Smart specialisation, Industry 4.0 and lagging regions: Some directions for policy. Regional Studies, Regional Science 7: 318-32. [CrossRef]

Bataev, Alexey V. 2018. Analysis and development the digital economy in the world. Paper Presented at 31st IBIMA Conference, Milan, Italy, April 25-26; pp. 61-71.

Bataev, Aleksey V., Alexandr A. Gorovoy, and Angela Mottaeva. 2018. Evaluation of the future development of the digital economy in Russia. Paper Presented at 32nd IBIMA Conference, Seville, Spain, November 15-16; pp. 88-101.

Blizkyi, Roman S. 2015. Resource conservation and transparency of relations under current economic development. Actual Problems of Economics 9: 108-13.

Bodrunov, Sergei D. 2018. Reindustrialization and formation of the "Digital economy": Harmonization of trends through the process of innovative development. New Zealand Management 2: 43.

Cavusgil, Tamer S. 2021. Advancing knowledge on emerging markets: Past and future research in perspective. International Business Review 30: 101796. [CrossRef]

Chae, Bongsug, and Gyuhyeong Goh. 2020. Digital Entrepreneurs in Artificial Intelligence and Data Analytics: Who Are They? Journal of Open Innovation: Technology, Market, and Complexity 6: 56. [CrossRef]

Clegg, Sue. 2011. Academic identities re-formed? Contesting technological determinism in accounts of the digital age. Contemporary Social Science 6: 175-89. [CrossRef]

De Gaetano, Davide. 2018. Forecast Combinations in the Presence of Structural Breaks: Evidence from U.S. Equity Markets. Mathematics 6: 34. [CrossRef]

Degtereva, Viktoriia A., Maxim V. Ivanov, and Anton A. Barabanov. 2019. Issues of building a digital economy in modern Russia. Paper Presented at European Conference on Innovation and Entrepreneurship, Kalamata, Greece, September 19-20; pp. 246-53.

Deloitte Insights. 2019. How Leaders are Navigating the Fourth Industrial Revolution: Our Latest Survey of Industry 4.0 Readiness. Available online: https://www2.deloitte.com/us/en/insights/deloitte-review/issue-22/industry-4-0-technologymanufacturing-revolution-2019.html (accessed on 10 February 2021).

Dmitriev, Nikolay. 2018. Assessment of the intellectual capital of an organization by identifying its economic potential. Economics and Management: Collection of Scientific Papers of St. Petersburg State University of Economics 2: 115-23.

Dmitriev, Nikolay D., Andrey Zaytsev, Viktoriia Degtereva, and Oleg Kichigin. 2020a. Construction of the Methodic Assess Economic Efficiency from the Implementation of an Investment Project of Introduce Lean Production Tools. Paper Presented at 35th IBIMA Conference, Seville, Spain, April 1-2; pp. 12119-30.

Dmitriev, Nikolay, Andrey Zaytsev, and Lyudmila Dubanevich. 2020b. Determining the strategic prospects of an enterprise by assessing the dynamics of its intellectual rent. Montenegrin Journal of Economics 16: 187-97. [CrossRef]

Ergunova, Olga, Alexey Skuratov, Olga Pozdeeva, and Alexandr Y. Kindaev. 2019. Opportunities and emerging trends for digitalization of Russian economy. Paper Presented at IOP Conference Series: Materials Science and Engineering, Volgograd, Russia, November 20-21; p. 012115.

Galbraith, John W., and Douglas J. Hodgson. 2018. Econometric Fine Art Valuation by Combining Hedonic and Repeat-Sales Information. Econometrics 6: 32. [CrossRef]

Ghauri, Pervez N., Roger N. Strange, and Fang Lee Cooke. 2021. Research on international business: The new realities. International Business Review 30: 101794. [CrossRef]

Glazyev, Sergei Y., Aleksandr E. Ajvazov, and Vladimir A. Belikov. 2018. The future of the world economy is an integrated world economic structure. Economy of Region 14: 1-12. [CrossRef]

Graham, Stephen, and Simon Guy. 2002. Digital space meets urban place: Sociotechnologies of urban restructuring in downtown San Francisco. City 6: 369-82. [CrossRef]

Grodach, Carl, and Chris Gibson. 2019. Advancing Manufacturing? Blinkered Visions in U.S. and Australian Urban Policy. Urban Policy and Research 37: 279-93. [CrossRef]

Hyland-Wood, Bernadette, John Gardner, Julie Leask, and Ullrich K.H. Ecker. 2021. Toward effective government communication strategies in the era of COVID-19. Humanities and Social Sciences Communications 8: 30. [CrossRef]

Irons, Alastair, and Harjinder Singh Lallie. 2014. Digital Forensics to Intelligent Forensics. Future Internet 6: 584-96. [CrossRef]

Juglar, Clement. 1862. Des Crises Commerciales et Leur Retour Periodique en France, en Angleterre, et aux Etats-Unis. Available online: https:/ / gallica.bnf.fr/ark:/12148/bpt6k1060720 (accessed on 10 February 2021).

Khin, Sabai, and Theresa C.F. Ho. 2020. Digital technology, digital capability and organizational performance: A mediating role of digital innovation. International Journal of Innovation Science 11: 177-95. [CrossRef]

Kichigin, Oleg, Viktoriia Degtereva, Andrey Zaytsev, and Nikolay Dmitriev. 2019. Application of the Game-Theoretic Method in the Development of an Investment Behavior Strategy. Paper Presented at 34th IBIMA Conference, Madrid, Spain, November 3-14; pp. 3532-40.

Kingiri, Ann Njoki, and Xiaolan Fu. 2020. Understanding the diffusion and adoption of digital finance innovation in emerging economies: M-Pesa money mobile transfer service in Kenya. Innovation and Development 10: 67-87. [CrossRef] 
Ko, Chuan-Chuan, Tyrone T. Lin, Fu-Min Zeng, and Chien-Yu Liu. 2018. Optimum Technology Product Life Cycle Technology Innovation Investment-Using Compound Binomial Options. Risks 6: 98. [CrossRef]

Kolyasnikov, Maksim S., and Natalya R. Kelchevskaya. 2020. Knowledge management strategies in companies: Trends and the impact of industry 4.0. The Manager 11: 82-96. [CrossRef]

Kondratieff, Nikolai D. 1984. The Long Wave Cycle. New York: Richardson \& Snyder, p. 138. First published 1925. [CrossRef]

Kotishwar, Annadi. 2020. Impact of blockchain technology on efficiency of financial transactions. Indian Journal of Finance 14: 36-44. [CrossRef]

Laitsou, Eleni, Antonios Kargas, and Dimitris Varoutas. 2020. Digital Competitiveness in the European Union Era: The Greek Case. Economies 8: 85. [CrossRef]

Lapidus, Larisa V., Lidiya S. Leontieva, and Aleksandr O. Gostilovich. 2019. Minimum digital basket of Russian regions for industrial transformation. E-Journal. Public Administration 77: 212-28. [CrossRef]

Lynn, Theo, Pierangelo Rosati, Binesh Nair, and Ciáran Mac an Bhaird. 2020. An Exploratory Data Analysis of the \#Crowdfunding Network on Twitter. Journal of Open Innovation: Technology, Market, and Complexity 6: 80. [CrossRef]

Maresova, Petra, Ivan Soukal, Libuse Svobodova, Martina Hedvicakova, Ehsan Javanmardi, Ali Selamat, and Ondrej Krejcar. 2018. Consequences of Industry 4.0 in Business and Economics. Economies 6: 46. [CrossRef]

Maskuriy, Raihan, Ali Selamat, Petra Maresova, Ondrej Krejcar, and Oladipo Olalekan David. 2019. Industry 4.0 for the construction industry: Review of management perspective. Economies 7: 68. [CrossRef]

Maydanova, Svetlana, and Igor Ilin. 2019. Strategic approach to global company digital transformation. Paper Presented at 33rd IBIMA Conference, Granada, Spain, April 10-11; pp. 8818-33.

Nikitina, Alena S., and Aleksey V. Ruchkin. 2019. Innovation potential of the modern Russian civil servants in public administration. Paper Presented at IOP Conference Series: Earth and Environmental Science, Russky Island, Russia, March 4-6; p. 032227.

Nurk, Jochen. 2021. Smart information system capabilities of digital supply chain business models. European Journal of Business Science and Technology 23: 143-84. [CrossRef]

Okhrimenko, Igor, Anna Lukyanova, Inna Sovik, and Svetlana Pyankova. 2019. Digital transformation of the socioeconomic system: Prospects for digitalization in society. Espacios 40: 26.

Ovchinnikov, Alexey I., Alexey Y. Mamychev, Tatyana S. Yatsenko, Artur G. Kravchenko, and Yurii A. Kolesnikov. 2020. Artificial intelligence in enforcement: Epistemological analysis. Journal of Politics and Law 13: 75-81. [CrossRef]

Park, Sohyun, and Yangmi Koo. 2020. Impact of proximity on knowledge network formation: The case of the Korean steel industry. Area Development and Policy. [CrossRef]

Rakhmeeva, Irina I. 2019. The digitalization in the service the asessment of regulatory legal acts. Paper Presented at Advances in Economics, Business and Management Research, Yekaterinburg, Russia, April 14-15; pp. 178-81.

Rayevnyeva, Olena V., and Tarik Touzani. 2021. Models of forecasting of enterprise's behavior in non-stationary external environment. Estudios de Economia Aplicada 38: 3998. [CrossRef]

Rimmer, Matthew. 2017. Back to the Future: The Digital Millennium Copyright Act and the Trans-Pacific Partnership. Laws 6: 11. [CrossRef]

Rodionov, Dmitry, Eugene Konnikov, and Olga Konnikova. 2018. Approaches to ensuring the sustainability of industrial enterprises of different technological levels. Journal of Social Sciences Research 3: 277-82.

Schou, Jannick, and Morten Hjelholt. 2019. Digital state spaces: State rescaling and advanced digitalization. Territory, Politics, Governance 7: 438-54. [CrossRef]

Schumpeter, Joseph A. 1939. Business Cycles. A Theoretical, Historical and Statistical Analysis of the Capitalist Process. New York: McGraw-Hill Book Company, Inc.

Spilnyk, Iryna, Ruslan F. Brukhanskyi, and Olexiy Yaroshchuk. 2020. Accounting and Financial Reporting System in the Digital Economy. Paper Presented at 10th International Conference on Advanced Computer Information Technologies, Deggendorf, Germany, September 16-18; pp. 81-584. [CrossRef]

Ustinovich, Elena S., Svetlana V. Mamontova, and Michael V. Kulikov. 2020. Digital economy and digitalization of AIC. In Advances in Economics, Business and Management Research. Vladivostok: Far Eastern Federal University, pp. 1903-5.

Vasetskaya, Natalia, and Tatiana Gaevskaia. 2019. Digitalization as an instrument for economic growth. Paper Presented at 33rd IBIMA Conference, Granada, Spain, April 10-11; pp. 8914-19.

Vukovic, Darko B., Dejan Radulovic, Milos Markovic, Dmitry M. Kochetkov, and Natalya Y. Vlasova. 2017. Development of a financial framework for the national plan for regional development: The evidence from Serbia. Economy of Region 13: 1314-28. [CrossRef]

WEF. 2018. Digital Transformation Initiative. Unlocking $\$ 100$ Trillion for Business and Society from Digital Transformation. Executive Summary. Available online: https:/ / reports.weforum.org/digital-transformation/wp-content/blogs.dir/94/mp/files/pages/ files/dti-executive-summary-20180510.pdf (accessed on 10 February 2021).

Yakovlev, Alexander, Tatyana Lebedeva, Svetlana Malyutenkova, and Natalya Kepp. 2019. Methodological fundamentals of quality management theory in condition of digital economy. Paper Presented at IOP Conference Series: Materials Science and Engineering, Saint-Petersburg, Russia, November 21-22; p. 497.

Zaytsev, Andrey. 2020. Rental income structure in economy as a basis for sustainable agrarian relations in the agro-industrial complex. Sustainability 12: 18. [CrossRef] 
Zaytsev, Andrey, Nikolay Dmitriev, and Sergey Talerchik. 2020. Intellectual Rent as A Necessary Element in The Transition to Noonomics. Paper Presented at 35th IBIMA Conference, Seville, Spain, April 1-2; pp. 13560-70.

Zhilenkova, Elena, Marina Budanova, Nikolay Bulkhov, and Dmitry Rodionov. 2019. Reproduction of intellectual capital in innovativedigital economy environment. Paper Presented at IOP Conference Series: Materials Science and Engineering, Saint-Petersburg, Russia, November 21-22; p. 497.

Ziaei Nafchi, Majid, and Hana Mohelska. 2018. Effects of Industry 4.0 on the Labor Markets of Iran and Japan. Economies 6: 39. [CrossRef]

Zimmerling, Amanda, and Xiongbiao Chen. 2021. Innovation and possible long-term impact driven by COVID-19: Manufacturing, personal protective equipment and digital technologies. Technology in Society 65: 101541. [CrossRef] 